\title{
Prevalence of Parascaris equorum in native horses in West Bank Palestine
}

\author{
R. Othman* and I. Alzuheir \\ Department of Veterinary Medicine, An Najah National University, Nablus, Palestine, *email: ratebothman@najah.edu
}

(Received 15, September 2018; Accepted 5 January, 2019)

\begin{abstract}
A total number of 435 fecal samples from native horses, aged between 6 months to 10 years of both sexes, were collected from eight cities at West Bank, Palestine during January 2015 to January 2017. The Mc Master egg counting and sedimentation methods were used for the detection of Parascaris equorum eggs in the collected samples. The overall prevalence rate of Parascaris equorum was found to be $15.6 \%$ (68 out of 435), and this rate varied significantly depending on the city. The highest prevalence rate was in Jericho $41.1 \%$ followed by Hebron $26.3 \%$, Jenin $19.4 \%$, Qalqilya $19.4 \%$, Tulkarm $12.2 \%$, Nablus $11.8 \%$ and Ramallah 5.3\%. The results revealed also that there was no significant difference in the prevalence rate of Parascaris equorum between male $15 \%$ and female $16.5 \%$ as well as between young $17.6 \%$ and adult $10.9 \%$ horses.
\end{abstract}

Keywords: Horses, Palestine, Parascaris equorum, Prevalence

Available online at http://www.vetmedmosul.com

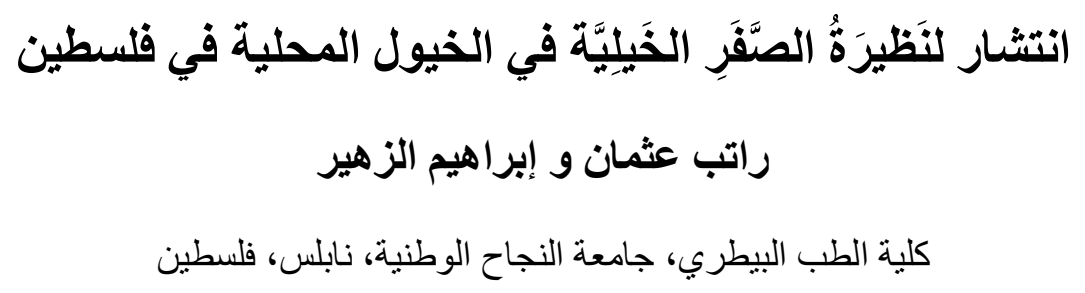

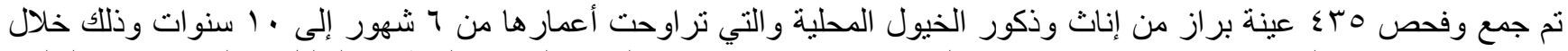

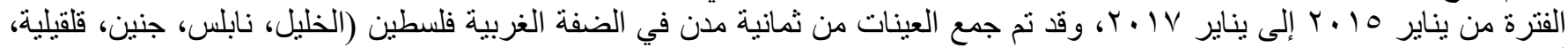

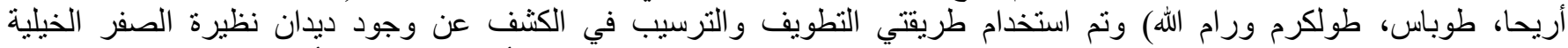

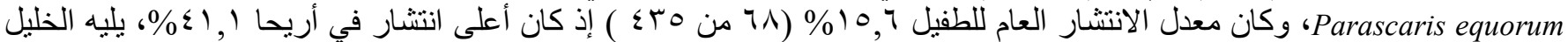

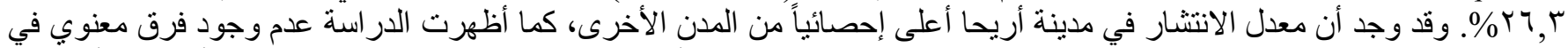

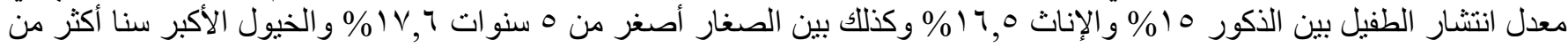

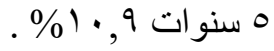

\section{Introduction}

Horses are domestic animals that have traditional and economic importance in Palestine. The total number of domestic horses has increased last few years in the country due to importance of horses as working animals as well as the establishment of new equestrian sport clubs (1). However, horses care and keeping system still depend on the traditional methods. There is no modernized farm or individual stables for each animal and inadequate veterinary care. Therefore, these traditional methods have negative effects on animal health and production which enhance the prevalence of the infectious diseases including internal parasite. The Parascaris equorum is a species of Ascarididae family belongs to the phylum Nematoda (Roundworms), and is considered one of the parasitic diseases that have a significant impact on equine health, performance and production (2). Horses get the infection via contaminated feed with infected eggs disseminated in the environment. Upon infection, several clinical appear on the infect animals such as respiratory distress, weight loss, growth retardation and colic. Furthermore, the infected 
animals have a dull hair and rusty appearance due to minerals deficiency. Heavy infestation of adult worms may cause intestinal impaction which lead to a fatal intestinal perforation or rupture (3-5). Considering the significance of this parasite and the lack of previous studies about it, we conducted this study to investigate the prevalence of Parascaris equorum in native-horses in West Bank, Palestine.

\section{Materials and methods}

\section{Samples and area of study}

The study was conducted in the period from January 2015 to January 2017 in eight cities in West Bank, Palestine (Nablus, Jenin, Tubas, Qalqilya, Tulkarm, Ramallah, Hebron and Jericho). The study included 435 fecal samples from both sexes of native horses $(253$ males and 182 females), aged between 6 months to 10 years. The samples were taken directly from the rectum of the animal or collected from the ground immediately after the defecation. The samples were transferred in an ice box to the laboratory of veterinary parasitology of the faculty of veterinary medicine at An-Najah University.

\section{Fecal examination}

The McMaster egg counting flotation and sedimentation methods were used for identification of Parascaris equorum eggs in the fecal samples (5). Two grams of feces were mixed with $28 \mathrm{ml}$ of saturated saline solution. Then, the mixture was filtered using a strainer and $0.5 \mathrm{ml}$ transferred to McMaster slide. The counting chamber was left to stand for 5 minutes, to allow the eggs for floating. The eggs were counted under the microscope at $10 \mathrm{x}$ magnification. The average of two fields was multiplied by a 50 to determine the number of eggs per gram of feces. The eggs morphology has also been examined, based on the outer shape, to discriminate between them $(5,6)$. Furthermore, the sedimentation method of fecal samples was used for detection the eggs and larvae according to their weight (5).

\section{Organ samples}

Three gastrointestinal tracts from recently necropsied horses of both sexes ( 2 males, 1 female), aged between 7 to 10 months, were examined for internal parasites in the Department of Veterinary Medicine at An-Najah University.

\section{Statistical analysis}

Statistical Analysis was done by applying Chi-square test SPSS statistics software package: Release 16.0 standard version, SPSS Inc., Chicago, IL. The differences of parasite prevalence were considered significant at $\mathrm{P}<0.05$.

\section{Results}

Results revealed that the overall prevalence rate of Parascaris equorum in native horses was $15.6 \%$ (68/435), this rate varied significantly depending on the cites .The highest prevalence rate was recorded in Jericho $70 \%(7 / 17)$, followed by Hebron 26.3\% (5/19), Jenin 19.4\% (19/98), 19.4\% Qalqilya (13/67), 12.2\% Tulkarm (14/115), $11.8 \%$ Nablus (4/34) and Ramallah 5.3\% (3/57) (Table 1).

Table 1: The prevalence rates of Parascaris equorumin native horses in eight cities at West Bank, Palestine

\begin{tabular}{lccc}
\hline City & $\begin{array}{c}\text { Samples } \\
\text { analyzed (N) }\end{array}$ & $\begin{array}{c}\text { Positive } \\
\text { samples (N) }\end{array}$ & $\begin{array}{c}\text { Prevalence } \\
\text { rate }(\%)\end{array}$ \\
\hline Jenin & 98 & 19 & $19.4^{\mathrm{a}}$ \\
Ramallah & 57 & 3 & $5.3^{\mathrm{a}}$ \\
Tulkarm & 115 & 14 & $12.2^{\mathrm{a}}$ \\
Hebron & 19 & 5 & $26.3^{\mathrm{a}}$ \\
Nablus & 34 & 4 & $11.8^{\mathrm{a}}$ \\
Tubas & 28 & 3 & $10.7^{\mathrm{a}}$ \\
Jericho & 17 & 7 & $41.1^{\mathrm{b}}$ \\
Qalqilya & 67 & 13 & $19.4^{\mathrm{a}}$ \\
\hline Total & 435 & 68 & 15.6 \\
\hline
\end{tabular}

Pearson Chi-Square. Each subscript letter denotes a subset of state categories whose column proportions do not differ significantly from each other at $\mathrm{P}<0.05$.

The prevalence rates according to sex are presented in the Table 2, out of 253 male samples analyzed, 38 were positive with the prevalence rate of $15 \%$. While in the female samples, 30 out of 182 were positive with prevalence rate of $16.5 \%$. There is no significant difference between the prevalence of Parascaris equorum infection in equine population according to the sex (Table2).

Table 2: The prevalence rates of Parascaris equorumin native horses based on the sex

\begin{tabular}{lccc}
\hline Sex & $\begin{array}{c}\text { Samples } \\
\text { analyzed (N) }\end{array}$ & $\begin{array}{c}\text { Positive } \\
\text { samples (N) }\end{array}$ & $\begin{array}{c}\text { Prevalence } \\
\text { rate }(\%)\end{array}$ \\
\hline Male & 253 & 38 & $15.0^{\mathrm{a}}$ \\
Female & 182 & 30 & $16.5^{\mathrm{a}}$ \\
\hline Total & 435 & 68 & 15.6 \\
\hline
\end{tabular}

Pearson Chi-Square. Each subscript letter denotes a subset of state categories whose column proportions do not differ significantly from each other at $\mathrm{P}<0.05$.

Furthermore, the results revealed that there was no significant difference $(\mathrm{P}<0.05)$ in the prevalence rate of Parascaris equorum between young horses $17.6 \%$ (54/306), less than 5 years, and adult10.9\% (14/129), more than 5 years (Table 3 ). 
Table 3: The prevalence rates of Parascaris equorumin native horses based on the age

\begin{tabular}{lccc}
\hline Age & $\begin{array}{c}\text { Samples } \\
\text { analyzed }(\mathrm{N})\end{array}$ & $\begin{array}{c}\text { Positive } \\
\text { samples }(\mathrm{N})\end{array}$ & $\begin{array}{c}\text { Prevalence } \\
\text { rate }(\%)\end{array}$ \\
\hline$<5$ years & 306 & 54 & $17.6^{\mathrm{a}}$ \\
$>$ 5 years & 129 & 14 & $10.9^{\mathrm{a}}$ \\
\hline Total & 435 & 68 & 15.6 \\
\hline
\end{tabular}

Pearson Chi-Square. Each subscript letter denotes a subset of state categories whose column proportions do not differ significantly from each other at $\mathrm{P}<0.05$.

The postmortem investigation of three foals, aged between 7 and 10 months, have revealed heavy infestation of Parascaris equorum in the small intestine (Figure 1).

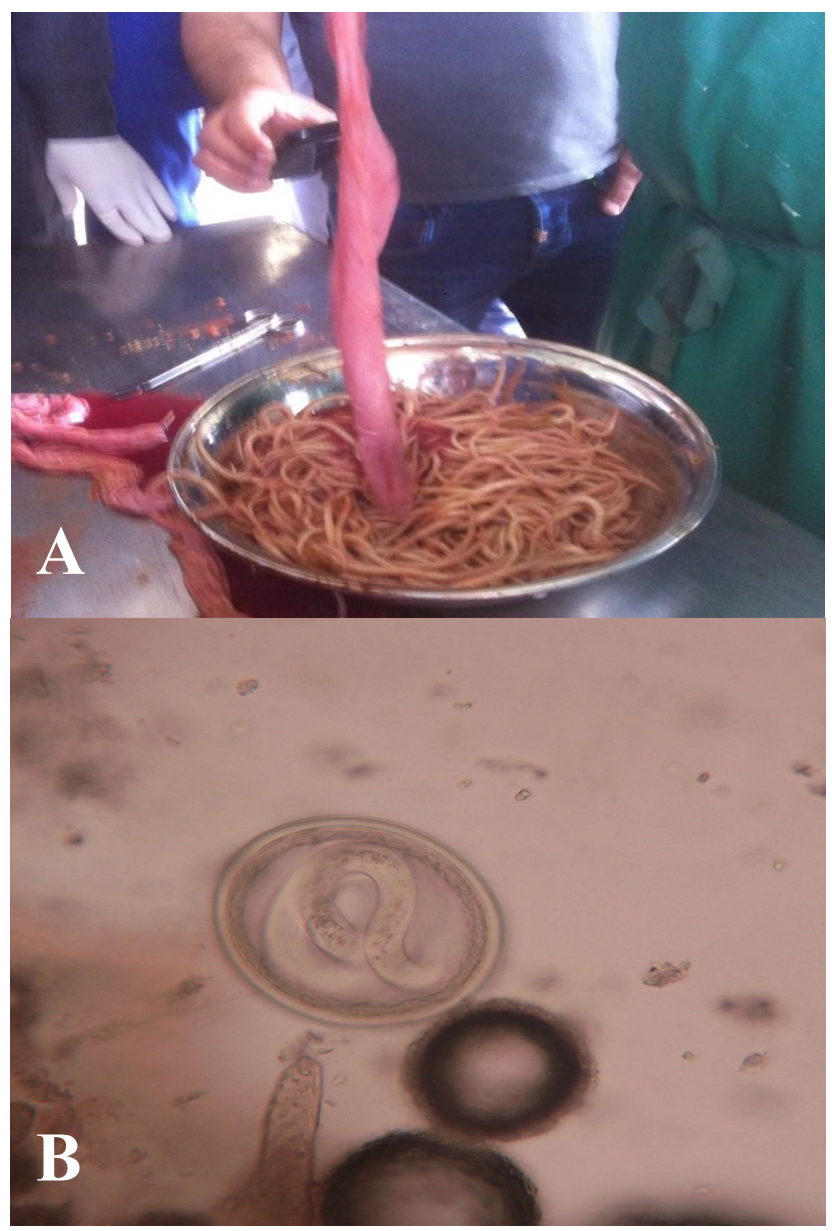

Figure 1: Severe infestation with Parascaris equorum (roundworm) in 3 months foal. A) High numbers of Parascaris equorum encountered small intestine of a necropsied 3 months foal. B) Parascaris equorum embryonated egg.

\section{Discussion}

In the current study, a survey was conducted as preliminary attempt to investigate the prevalence of intestinal Parascaris equorum in the native horses from eight cities in West Bank, Palestine. Cases of sub-acute or chronic endoparasites infestation have led to economic losses in horses, either due to decreased productivity or increased mortality in the affected animals. The results of this study showed that Parascaris equorum was found in horses of different ages at all the West Bank, Palestinian cities with different prevalence rates. The overall prevalence rate was found to be $15.6 \%$. Jericho city which was significantly higher than other cities.

This higher rate of infection in Jericho city might be due to the number of analyzed samples that was lower than the other investigated cities. The conditions of horses keeping and management in all cities were similar except for Ramallah city, in which the samples were taken from one equestrian club, where the horse keeping and management vary in terms of hygiene and horse care. This explains the lowest percentage rate of infection that found in Ramallah city. The horses in the current study were mostly restrained to stables and occasionally allowed to graze in open fields or on hand cut grasses. When contaminated, the pasture environment or hand cut grasses could result in infection or re-infection of susceptible animals.

The prevalence rate of infection in all the cities covered by the current study was in the range of other studies worldwide. In Erbil (Iraq), the prevalence rate was 19.56\%, while it was $40.90 \%$ in Diwaniyah city (7). Some studies performed in other developing countries showed higher prevalence rate of infection. For instance, reported $50 \%$ in Ethiopia, (8) $47.50 \%$ in India (9) and $18.48 \%$ in Cameroon (10). Studies from other countries vary in the prevalence rate; in some regions of Germany, the prevalence rate of infection was $16.7 \%$ (11), 5\% prevalence rate in Australia (12) and in Brazil (13). This variation is mainly related to the number of the tested horses and the nature of their lives and methods of horse keeping and care from one country to another. In addition, the variability of climatic conditions in terms of temperature and humidity between geographical regions in most countries may affect the prevalence rate (14).

Our results showed no effect of the sex on the prevalence rate of infection. This finding is in agreement with other studies in other regions; for example; in India, the prevalence rates in females and males were $60.97 \%$ and $58.51 \%$ respectively. (9). Singh et al. (14) 2012 reported that the prevalence rate in females was $75.73 \%$ and in males was $72.30 \%$ in India (14). The non-significant differences in prevalence rate between the two sexes may be due to the methods of keeping and nutrition which are very similar as 
the animals kept together without special grazing, feeding or management differences (15).

Interestingly, in the present study, there was no significant difference of prevalence rate between the young horses $17.6 \%$, less than 5 years, compared to the adult $10.9 \%$. This finding is inconsistence with other studies in other regions. Tolliver et al (16) 1987 reported that the prevalence rate in horses less than 2 years was $50 \%$, while in adult horses was $23 \%$ (16). In another study, the percentage of intestinal worms in horses less than 3 years old was $75 \%$ compared to the horses less than 10 years $70 \%$, while it was $42 \%$ in horses more than 11 years old (9). In some areas of Iraq, the prevalence rate in horses under 5 years of age was $84 \%$, and $61.1 \%$ in horses older than 5 years (17).

This variation may be attributed to the number of sample size and analysis techniques which were used. Other factors might be the fact that the different ages have most likely had no or infrequent treatment with anthelmintic. In addition, both groups of animals are kept in the same conditions, usually grazing at the same pasture (15).

\section{Conclusions}

Our study demonstrated that the Parascaris equorum infestation was present in horses of all West Bank, Palestinian cities and among different ages. Knowledge about the prevalence of internal helminthes will allow the application of specific treatment and horse care management to reduce the prevalence rate. In order to reduce the prevalence rate is recommended to more attention to the hygiene of stables and breeding farms, as well as caring for pastures. A regular deworming program with efficacious anthelmintic should be carried out. Changing the anthelmintic type from time to time is necessary to prevent resistance. Proper screening and monitoring of the horses should be carried out regularly to evaluate these measurements.

\section{Refernces}

1. Livestock Survey, 2013 - Main Results. Palestinian central bureau of statistics: Ramallah, Palestine, 2014; 63.
2. Clayton HM. Ascarids: Recent advances. Equine Practice. 1986;2:313-328. https://doi.org/10.1016/S0749-0739(17)30718-6

3. Laugier C, Sevin C, Menard S, Maillard K. Prevalence of Parascaris equorum infection in foals on French stud farms and first report of ivermectin-resistant $P$. equorum populations in France. Vet Parasitol. 2012;188:185-189.

4. Upjohn MM, Shipton K, Lerotholi T, Attwood G, Verheyen KL. Coprological prevalence and intensity of helminth infection in working horses in Lesotho. Trop Anim Health Pro. 2010;42:16551661. https://link.springer.com/article/10.1007/s11250-010-9617-z

5. Soulsby E. Helminths, arthropods and protozoa of domestic animals. $7^{\text {th }}$ ed. New York: Bailier Tindall; 1982; pp: 143-157

6. Sloss MW, Kemp RL. Veterinary clinical parasitology. Iowa: Iowa State University Press; 1978.

7. Wannas H, Dawood KA, Gassem G. Prevalence of gastro-intestinal parasites in horses and donkeys in al Diwaniyah Governorate. QJVMS.2012;11:148-155. http:// www. qu. edu. iq/ journalvm/ index. $\mathrm{php} / \mathrm{vm}$ journal/article/view/382

8. Ayele GFG, Bojia E, Joe A. Prevalence of gastro-intestinal parasites of donkeys in Dugda Bora District, Ethiopia. Livest Res Rural Develop. 2006;18:14-21.

9. Yadav KS, Shukla PC, Gupta DK, Mishra A. Prevalence of gastrointestinal nematodes in horses of Jabalpur region. Res J Vet Pract. 2014; 2: 44-48. $48 \mathrm{http} / / \mathrm{dx}$. doi. org/ 10. 14737/ journal.rjvp/2014/2.3.44.48

10. Lem MF, Vincent KP, Pone JW, Joseph T. Prevalence and intensity of gastro-intestinal helminths in horses in the Sudano-Guinean climatic zone of Cameroon. Trop parasitol. 2012;2:45. doi: 10.4103/22295070.97239

11. Hinney B, Wirtherle NC, Kyule M, Miethe N, Zessin KH, Clausen $\mathrm{PH}$. Prevalence of helminths in horses in the state of Brandenburg, Germany. Parasitolo Res. 2011;108:1083. https://link.springer.com/article/10.1007/s00436-011-2362-z

12. Bucknell D, Gasser R, Beveridge I. The prevalence and epidemiology of gastrointestinal parasites of horses in Victoria, Australia. Int $\mathrm{J}$ Parasitol. $1995 ; 25: 711-724$. https://pdfs.semanticscholar.org/bf7c/7758dfeac79c51d800b55fc6f189 414205fd.pdf

13. Pereira J, Vianna S. Gastrointestinal parasitic worms in equines in the Paraíba Valley, State of São Paulo, Brazil. Vet Parasitol. 2006;140:289-295. https://doi.org/10.1016/j.vetpar.2006.03.036

14. Singh G, Soodan J, Singla L, Khajuria J. Epidemiological studies on gastrointestinal helminths in horses and mules. Vet Pract. 2012;13:2327. https://www.cabdirect.org/cabdirect/abstract/20133045674

15. Kornaś S, Cabaret J, Skalska M, Nowosad B. Horse infection with intestinal helminths in relation to age, sex, access to grass and farm system. Vet Parasitol. 2010;174:285-291. https:/ / doi. org/ 10.1016 /j.vetpar.2010.09.007

16. Tolliver S, Lyons E, Drudge J. Prevalence of internal parasites in horses in critical tests of activity of parasiticides over a 28-year period (1956-1983) in Kentucky. Vet Parasitol. 1987;23:273-284. https://doi.org/10.1016/0304-4017(87)90013-6

17. Nhq I. K. Zangana KJ, Aziz ZI, Hassan D. Prevalence of gastrointestinal parasites in horses in Erbil province. North Iraq AlAnbar J Vet Sci. 2013;6:77-82. 